\title{
Insecticide resistance status in Anopheles gambiae in southern Benin
}

\author{
Anges W Yadouleton ${ }^{1 *}$, Gil Padonou ${ }^{1}$, Alex Asidi ${ }^{3}$, Nicolas Moiroux ${ }^{1,2}$, Sahabi Bio-Banganna ${ }^{1}$, Vincent Corbel ${ }^{1,2}$, \\ Raphael N'guessan ${ }^{1,3}$, Dina Gbenou ${ }^{4}$, Imorou Yacoubou ${ }^{5}$, Kinde Gazard ${ }^{6}$, Martin C Akogbeto ${ }^{1}$
}

\begin{abstract}
Background: The emergence of pyrethroid resistance in Anopheles gambiae has become a serious concern to the future success of malaria control. In Benin, the National Malaria Control Programme has recently planned to scaling up long-lasting insecticidal nets (LLINs) and indoor residual spraying (IRS) for malaria prevention. It is, therefore, crucial to monitor the level and type of insecticide resistance in An. gambiae, particularly in southern Benin where reduced efficacy of insecticide-treated nets (ITNs) and IRS has previously been reported.

Methods: The protocol was based on mosquito collection during both dry and rainy seasons across forty districts selected in southern Benin. Bioassay were performed on adults collected from the field to assess the susceptibility of malaria vectors to insecticide-impregnated papers (permethrin $0.75 \%$, delthamethrin $0.05 \%$, DDT $4 \%$, and bendiocarb $0.1 \%$ ) following WHOPES guidelines. The species within An. gambiae complex, molecular form and presence of $k d r$ and ace-1 mutations were determined by PCR.

Results: Strong resistance to permethrin and DDT was found in An. gambiae populations from southern Benin, except in Aglangandan where mosquitoes were fully susceptible (mortality 100\%) to all insecticides tested. PCR showed the presence of two sub-species of An. gambiae, namely An. gambiae s.S, and Anopheles melas, with a predominance for An. gambiae s.s (98\%). The molecular M form of An. gambiae was predominant in southern Benin (97\%). The kdr mutation was detected in all districts at various frequency (1\% to 95\%) whereas the Ace-1 mutation was found at a very low frequency $(\leq 5 \%)$.
\end{abstract}

Conclusion: This study showed a widespread resistance to permethrin in An. gambiae populations from southern Benin, with a significant increase of kdr frequency compared to what was observed previously in Benin. The low frequency of Ace-1 recorded in all populations is encouraging for the use of bendiocarb as an alternative insecticide to pyrethroids for IRS in Benin.

\section{Background}

More than $90 \%$ of recorded malarial deaths occur in Africa among the most vulnerable low immune response individuals, such as children under five years old and pregnant women [1,2]. The National Malaria Control Programmes (NMCP) in African countries currently relies on strategies targeting mosquito vector control, which involve the use of long-lasting insecticidal nets (LLINs) and/or indoor residual spraying (IRS), the two most effective preventive measures. Both methods have shown to be very effective against Anopheles mosquitoes

\footnotetext{
* Correspondence: anges33@yahoo.fr

'Centre de Recherche Entomologique de Cotonou (CREC), 06 BP 2604
} Cotonou, République du Bénin
[3-8]. In 2010 in Benin, a full coverage of LLINs countrywide couple with IRS in the department of Ouémé in southern Benin will become a new tool to improve malaria prevention and control.

However, the development of pyrethroid resistance in populations of Anopheles gambiae has become a serious threat to the effectiveness of these two vector control measures [9]. N'Guessan et al [10] recently established a clear relationship between pyrethroid resistance caused by $k d r$ and the failure of LLINs and IRS in experimental huts in south Benin. In the last decade, the emergence of resistance in populations of Anopheles to common classes of insecticides used in public health has been reported in many African countries including Kenya [11], Côte d'Ivoire [12], Benin [13-15], Niger [16], 
Burkina Faso [17,18], Mali[19], Nigeria[20], South Africa [21], and Cameroun [22].

In West Africa, the main mechanism involved in pyrethroid-resistance in An. gambiae is caused by target site insensitivity through a knockdown resistance $(k d r)$-like mutation caused by a single point mutation (Leu-Phe) in the para-sodium channel gene [23]. Preliminary surveys done in Benin southern in An. gambiae populations by Corbel et al [14], indicated that the Leu-Phe kdr mutation has been found almost only in the $M$ form at high frequency (0.95).

Indeed, several authors reported that the use of insecticides in households and pesticides in agricultural settings has greatly increased selection pressure leading to the emergence of insecticide resistance in malaria vectors [13-15,24]. In Benin, it was reported that DDT resistance in An. gambiae sensu lato (s.l.) was the result of massive use of DDT house spraying applications in several districts of the country during the $\mathrm{WHO}$ malaria eradication campaign in the 1950s [25].

A study in Burkina Faso documented a relatively high frequency of $k d r$ mutations (Leu-Phe) in An. gambiae collected from cotton farms under massive insecticide treatment compared to farms with no pesticide utilization [18]. Therefore, several studies on insecticide resistance have currently been addressing the agenda of most malaria scientists in sub-Saharan Africa and around the world to approach in different ways the crucial issues of insecticide resistance in malaria vectors which threatens the effective usefulness of ITNs and IRS for malaria prevention $[6,26]$.

Previous resistance monitoring surveys conducted in Benin had focused on the south-north transect. It is then a priority to investigate the status of insecticide resistance in An. gambiae in southern Benin, because pyrethroid resistance has been reported with a clear evidence of reduced efficacy of ITNs and IRS in experimental huts $[10,26]$. In addition to the $k d r$ mutation, which is the main mechanism of resistance to pyrethroids, it's important to address also the distribution of the Ace.1 allele that causes resistance to organophosphates and carbamates. With support of Presidential Malaria Initiative (PMI), a large-scale programme based on free-ITN distribution in combination with IRS was implemented since 2008 in four districts in Department of Ouémé in southern Benin. To attain a better understanding of the resistance situation in Benin particularly in these localities because of the use of bendiocarb in IRS, it is important to characterize the spatial distribution of resistance in An. gambiae in a variety of ecological settings and then attempt to correlate this resistance with pesticide usage. The present study propose to assess the resistance status of malaria vectors to carbamates, pyrethroids and assessed the implications for vector control strategy in a new geographical setting of an opposite east-west transect of the southern part of Benin. This area has a different bioclimatic characteristic with high rainfall $(1,500 \mathrm{~mm}$ yearly), where insecticides are extensively used for both public health and agricultural purposes.

\section{Methods}

\section{Study areas}

The study was carried out in forty districts of southern Benin characterized by a continual practice of urban and peri-urban agriculture, with two rainy seasons (March- July and October- November) and two dry seasons (December-March and August-September). The annual mean rainfall is $1,500 \mathrm{~mm}$ in July, relative humidity (RH) of $70 \% \pm 5$ and a minimum/maximum temperature ranging from 23 to $32^{\circ} \mathrm{C}$. The choice of these environments is justified by their particular bioclimatic characteristics and the use of insecticides or fertilizers in public health and agriculture. Indeed, the presence of susceptible population of An. gambiae to pyrethroids and organophosphorous recorded in some districts will help to effectively use the IRS and ITNs in the study areas.

\section{Mosquito collections}

Mosquitoes were collected during the dry (from February to March) and the rainy seasons (April-July) across the forty districts selected in south Benin. Larvae and pupae were collected using the dipping on breeding sites and then kept in separated labelled bottles related to each locality. A part of the larvae samples was reared up to adult emergence at the CREC (Centre de Recherche Entomologique de Cotonou, Benin) insectary for further bioassay tests.

\section{Insecticide susceptibility test}

Females mosquitoes aged 2-5 days old were exposed to diagnostic doses of various insecticides for susceptibility tests using insecticide-impregnated papers, as described by the standard WHO testing protocol [27]. The following insecticides were tested: deltamethrin $(0.05 \%)$, permethrin $(0.75 \%)$, DDT $(4 \%)$ and bendiocarb $(0.1 \%)$. The emphasis was also put on deltamethrin, because of a nationwide distribution of PermaNets by the NMCP. The use of DDT is justified by the detection of crossresistance between pyrethroids and organo-chlorine in Anopheles populations. The carbamate bendiocarb was one of the alternative insecticides to pyrethroids currently used for IRS in Benin [28].

For each treatment, five test tubes were used: one untreated paper as a control and four treated papers to expose mosquitoes. Control tubes contained filter papers impregnated with silicon oil (insecticide carrier) only, 
whereas treated papers were impregnated with diagnostic doses of insecticide plus carrier.

An average of twenty-five mosquitoes was introduced into each tube. Females of An. gambiae used in this study were exposed for one hour to insecticide-treated papers and monitored at different time intervals $(10,15$, $20,30,45,60$ minutes) to record the "knock-down" times. After one-hour exposure, mosquitoes were transferred into holding tubes and provided with cotton wool wetted with a $10 \%$ honey solution. Mortalities were recorded after 24 hours and the susceptibility status of the population was graded according to the WHO recommended protocol [27]. Dead and survived mosquitoes from this bioassay were separately kept in Carnoy solution at $-20^{\circ} \mathrm{C}$ for further molecular characterization.

\section{Molecular characterization of Anopheles populations using PCR analysis}

In each locality, 25-35 females of An. gambiae samples from the WHO bioassays were analysed at the molecular level. PCR analysis for species identification [29] was performed to identify various members of An. gambiae complex collected in each site. The next set of PCR focused on molecular forms using PCR-RFLP [30], which involved only An. gambiae sensu stricto (s.s.). The PCR forms sub-grouped the An. gambiae s.s. into two molecular forms: An. gambiae s.s. $M$ and An. gambiae s.s. $S$ forms. The last series of PCRs determined the presence of $k d r$ mutations in An. gambiae ss. Populations, as described by Martinez-Torres et al [31]. The PCR-RFLP diagnostic test was used to detect the presence of G119S mutation (Ace.1 gene) as described by Weill et al [32].

\section{Data interpretation}

The resistant status of mosquito samples was determined according to the WHO criteria [27].

Following the WHO protocol

- Mortality rates is > 97\%: the population was considered fully susceptible

- Mortality rates ranged between $80>x<97 \%$ : resistance suspected in the population

- Mortality rates $<80 \%$, the population was considered resistant to the tested insecticides.

Mortality rates were corrected using Abbott formula when control mortality was above 5\% [33]. Molecular results (PCR Kdr and Ace-1) were compared to insecticide susceptibility tests performed with the WHO method to conclude on the An. gambiae status in the districts surveyed.

\section{Mapping insecticide resistance in mosquito vectors in southern Benin}

Using geographical information recorded with GPS, screened localities were projected on a map of southern
Benin where mosquito larvae were collected. Resistance data were obtained from 40 districts in 6 departments (Ouémé, Plateau, Littoral, Atlantique, Mono, Couffo) and spatialized using the ESRI ArcGis Software.

\section{Data analysis}

Analysis using the computer software Excel, Fisher's exact tests was performed on the data sets gathered from the localities surveyed. Parameter for analysis included the resistance status of each tested population of An. gambiae. The insecticide susceptibility test on resistant strains from different districts was compared and analysed using Statcalc-Epi-info software, to compare the status of insecticide resistance in the different sites investigated. A Fisher's exact test was performed to determine if there was any significant difference between two given sites.

\section{Results}

Resistance status

Additional file 1 shows the insecticide resistance status of An. gambiae s.l populations from the 40 districts of southern Benin. Following the exposure of females of An. gambiae to permethrin impregnated papers, all 40 populations were fully susceptible to deltamethrin and bendiocarb, 39 out of 40 were resistant to permethrin and 39 out of 40 showed resistant to DDT (see Additional file 1)

Identification of molecular forms of Anopheles gambiae s.s 1,500 mosquitoes from the 40 districts were successfully analysed by species, molecular forms. PCR revealed the presence of two sub-species of An. gambiae: An. gambiae s.s., and Anopheles melas with a predominance of An. gambiae s.s (98\%). The M form was predominant over the $\mathrm{S}$ form $(\mathrm{M}=98 \% ; \mathrm{S}=2 \%)$.

\section{Detection of resistance genes}

Allele and genotype frequencies at the $k d r$ and Ace.1 loci are shown in Additional file 2. Results from this study showed that the $k d r$ mutation was present in all An. gambiae populations collected from the different district. The highest frequencies were recorded in Dogbo, Lokossa and Lanta (96\%, 95\% and 95\%, respectively) and the lowest frequency was recorded in An. gambiae strains from Aglandan (1\%). The Ace-1 mutation was found in An. gambiae populations collected from the different districts but at very low frequency (from $1 \%$ to $5 \%$ ).

\section{Mapping insecticide resistance in mosquito vectors in southern Benin}

Using geographical information recorded with GPS, screened localities were projected on a map of Benin and areas of permethrin and bendiocarb resistance or 
susceptibility were marked. The map generated from this study showed a spread of resistance of permethrin in most districts of South Benin (Figure 1). However, the levels of resistance registered in the following localities, Sakété, Kétou, Lokossa, Dogbo, Comè and Lanta were relatively consistent compared to other sites of the districts. On the other hand, no resistance was found in, Houeyogbé, Aglangandan, and Ifangni, districts.

\section{Discussion}

The species composition of Anopheles gambiae complex identified during this study did not differ from those recorded in previous studies in Benin. It was shown that, within the An. gambiae complex, An. gambiae s.s. $M$ form was predominant (>98\%) and has as a wide distribution across southern Benin Corbel et al [14]. The same trend was found in some localities of Mali, Nigeria [34-36]. The absence of An. melas in many districts in southern Benin can be attributed to the fact that larvae were mostly sampled from pools and puddles rather than flooded water, which is the preferred breeding site of An. melas [37]. No An. arabiensis was found in the different localities.

The study showed a wide distribution of resistance in An. gambiae s.l. to permethrin and DDT in southern Benin whereas all samples of An. gambiae tested were fully susceptible to deltamethrin and bendiocarb. The widespread resistance to DDT and permethrin in southern Benin can be explained by a long-standing, massive use of DDT house-spraying in several districts of the country during the WHO malaria eradication programme in the 1950s [25]. In addition, the rapid expansion of urban agriculture is one of the major factors that contributes to a large distribution of pyrethroid resistance in An. gambiae s.l Corbel et al [14]. A recent report by Yadouleton et al [15] has confirmed that urban farming in Benin has enormously contributed to the emergence of resistance in Anopheles populations.

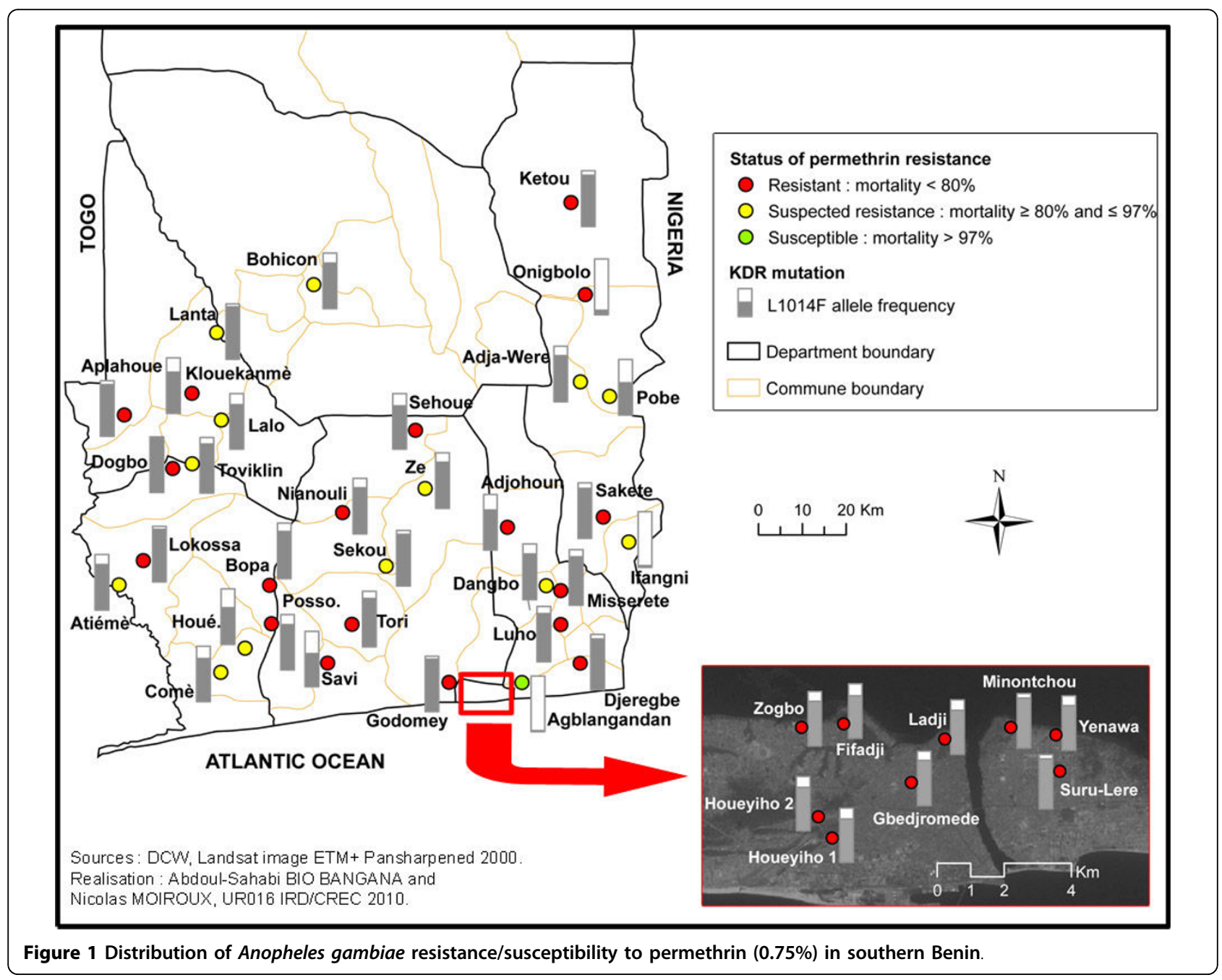


As reported by Akogbeto et al [24], some populations of An. gambiae lay their eggs in breeding sites containing insecticide residues. A study in vegetable farming in Benin [15] has shown that such activities in urban areas directly led to an improper use of insecticides to control vegetable pests, thus exerting a huge selection pressure on mosquito larval population. Moreover, the liberalization of the pesticide sector and the increased cost of pesticides registration have incited most of the farmers to illegally procure insecticides and an uncontrolled use of these chemicals in Benin. This factor has also contributed to the emergence of insecticide resistance in An. gambiae populations [15,24].

However, the absence of pyrethroid-DDT cross resistance in An. gambiae from Aglangandan in the Departement of Ouémé can be explained by the absence of agriculture activities in this area. Recently, qualitative data were collected from direct observations, in-depth interview and focus group discussions to confirm this hypothesis [15].

Some populations of An. gambiae have developed low resistance to bendiocarb in southern Benin. This can be explained by the fact that in these areas, carbamate and organophosphorous insecticides were mostly used by farmers for crop protection [38]. The results confirm those of Corbel et $a l$ [14] and Djogbenou et $a l$ [39] that previously showed a low frequency of the Ace1 allele in malaria vectors populations in Benin. This is particularly relevant to strengthen vector control campaigns using Indoor Residual Spraying based on carbamate and/or organophosphate as alternatives to pyrethroids, which are currently used by the NMCP in several areas of Benin.

\section{Conclusion}

The emergence of pyrethroid resistance in An. gambiae has become a serious concern for the success of malaria control in the last decades. To date, pyrethrinoids remain the only family of insecticides currently recommended by the WHO for the impregnation of bed nets. This study showed a relatively wide distribution of insecticide resistance in An. gambiae, especially to permethrin and DDT. The current findings will help for decision-making in the National Malaria Control Programme especially in the choice of insecticide to use during the next campaigns of Indoor Residual Spraying (IRS) in Benin.

Additional file 1: Percentage of dead Anopheles gambiae observed after 1 hour exposure to permethrin $(0.75 \%)$, bendiocarb $(0.1 \%)$, DDT $(4 \%)$, deltamethrin $(0.05 \%)$ in 6 departments in southern Benin.

Additional file 2: Species identification, molecular forms and frequency of the kdr, and Ace.1 alleles and genotypes in Anopheles gambiae s.l

\section{Acknowledgements}

This work was supported by the Presidential Malaria Initiative and Bill/ Melinda Gates and I am grateful to the CREC's team for technical assistance during laboratory bioassays and field collections.

\section{Author details}

'Centre de Recherche Entomologique de Cotonou (CREC), 06 BP 2604 Cotonou, République du Bénin. ${ }^{2}$ Institut de Recherche pour le Développement (IRD), UR016, Caractérisation et Contrôle des Populations de Vecteurs, 01 BP 4414 RP Cotonou, République du Bénin. ${ }^{3}$ London School of Tropical Medicine and Hygiene, London, UK. ${ }^{4}$ WHO-Benin. ${ }^{5}$ National Malaria Control Programme, Benin. ${ }^{6}$ Faculté des Sciences de la Santé, Benin.

\section{Authors' contributions}

AWY contributed to design of the study and conceived the protocol, proceed data analysis and interpretation. MCA, DG, KD, IY contributed to the study design, provided funding and coordination. GP, contributed in the study design and in the implementation of this research. BB and NM contributed to the mapping. AA, NR, VC contributed to manuscript drafting. All authors read and approved the final manuscript.

\section{Competing interests}

The authors declare that they have no competing interests.

Received: 9 September 2009 Accepted: 24 March 2010

Published: 24 March 2010

\section{References}

1. Lindblade KA, Walker ED, Onapa AW, Katungu J, Wilson ML: Highland malaria in Uganda: prospective analysis of an epidemic associated with El Nino. Trans R Soc Trop Med Hyg 1999, 93:480-487.

2. Malakooti MA, Biomndo K, Shanks GD: Reemergence of epidemic malaria in the highlands of western Kenya. Emerg Infect Dis 1998, 4:671-676.

3. Akogbéto M: Etude de la transmission du paludisme côtier lagunaire: Cas d'un village construit sur un lac d'eau saumâtre. Ann Soc Belge Méd Trop 1995, 75:219-227.

4. Beach R: International vector resistance testing Annual Meeting of the American Mosquito Control Association, Larch, Utah 1997, 23-27.

5. Carnevale P, Robert V, Boudin C, Halna JM, Pazart L-H, Gazin P, Richard A, Mouchet J: La lutte contre le paludisme par les moustiquaires imprégnées de pyréthrinoïdes au Burkina-Faso. Bull Soc Path Exot 1988, 81:832-842.

6. Coluzzi M, Petrarca V: Aspirator with paper cup for collecting mosquitoes and others insects. Ann Soc Belge Méd Trop 1973, 33:249-250.

7. Magesa SM, Wilkest J, Minzawa AEP, Myamba J, Philip MD: Trial of pyrethroid impregnated bed nets in area of Tanzania hole endemic of malaria. Part II. Effects on vector population. Acta Trop 1990, 49:97-108.

8. Service MV, Davidson G: A light incident of dieldrin resistance in An gambiae Giles from an unsprayed area in northern Nigeria. Nature 1964, 203:209-210.

9. Santolamazza Federica, Calzetta Maria, Etang Josiane, Barrese Elena, Dia Ibrahima, Caccone Adalgisa, Donnelly JMartin, Petrarca Vincenzo, Simard Frederic, Pinto Joao, Torre Alessandra della: Distribution of knockdown resistance mutations in Anopheles gambiae molecular forms in west and west-central Africa. Malar J 2008, 7:192.

10. N'Guessan R, Corbel V, Akogbeto M, Rowland M: Reduced efficacy of insecticide treated nets and indoor residual spraying for malaria control in pyrethroid resistance area, Benin. Emerg Infect Dis 2007, 13:199-206.

11. Vulule JM, Beach RF, Atieli FK, MCallister JC, Brogdon WG, Roberts JM, Mwangi RW, Hawley WA: Elevated oxidase and esterase levels associated with permethrin tolerance in Anopheles gambiae from Kenyan villages using permethrin impregnated nets. Med Vet Entomol 1999, 13:239-244.

12. Elissa N, Mouchet J, Rivière F, Meunier JY, Yao K: Resistance of Anopheles gambiae s.s. to pyrethroids in Côte d'lvoire. Ann Soc Belge Méd Trop 1993, 73:291-294.

13. Corbel V, Chandre F, Brengues C, Akogbeto M, Lardeux F, Hougard JM, Guillet P: Dosage-dependent effects of permethrin-treated nets on the behaviour of Anopheles gambiae and the selection of pyrethroid resistance. Malar J 2004, 3:22. 
14. Corbel V, N'Guessan R, Brengues C, Chandre F, Djogbenou L, Martin T, Akogbeto M, Hougard JM, Rowland M: Multiple insecticide resistance mechanisms in Anopheles gambiae and Culex quinquefasciatus from Benin, West Africa. Acta Trop 2007, 101:207-216.

15. Yadouleton AW, Asidi A, Djouaka RF, Braïma J, Agossou CD, Akogbeto MC Development of vegetable farming: a cause of the emergence of insecticide resistance in populations of Anopheles gambiae in urban areas of Benin. Malar J 2009, 8:103.

16. Czeher C, Labbo R, Arzika I, Duchemin JB: Evidence of increasing Leu-Phe knockdown resistance mutation in Anopheles gambiae from Niger following a nationwide long-lasting insecticide-treated nets implementation. Malar J 2008, 7:189.

17. Diabate A, Baldet T, Chandre F, Guiguemde RT, Brengues C, Guillet P, Hemingway J, Hougard JM: First report of the kdr mutation in Anopheles gambiae M form from Burkina Faso, West Africa. Parassitologia 2002, 44:157-158.

18. Diabate A, Baldet T, Chandre F, Akogbéto M, Guiguemde RT, Darriet F, Brengues C, Guillet P, Hemingway J, Graham JS, Hougard JM: The role of agricultural use of insecticides in resistance to pyrethroids in Anopheles gambiae s.l. in Burkina Faso. Am J Trop Med Hyg 2002, 617-622.

19. Fanello C, Petrarca V, Della Torre A, Santolamazza F, Dolo G, Coulibaly M, Alloueche A, Curtis CG, Toure YT, Coluzzi M: The pyrethroid knock-down resistance gene in the Anopheles gambiae complex in Mali and further indication of incipient speciation within An. gambiae s.s. Insect Mol Biol 2003, 12:241-245.

20. Awolola TS, Brooke BD, Koekemoer LL, Coetzee M: Resistance of the malaria vector Anopheles gambiae s.s. to pyrethroid insecticides, in south-western Nigeria. Ann Trop Med Parasitol 2002, 96:849-852.

21. Hargreaves K, Koerkemoer LL, Brooke B, Hunt RH, Mthembu J, Coetzee M: Anopheles funestus resistant to pyrethroid insecticides in South Africa. Med Vet Entomol 2000, 14:181-189.

22. Etang J, Manga L, Chandre F, Guillet P, Fondjo E, Mimpfoundi R, Toto JC, Fontenille D: Insecticide susceptibility status of Anopheles gambiae s.l. (Diptera: Culicidae) in the Republic of Cameroon. J Med Entomol 2003, 40:491-497.

23. Chandre F, Darriet F, Manga L, Akogbeto M, Faye O, Mouchet J, Guillet P: Status of pyrethroid resistance in Anopheles gambiae sensu lato. Bull World Health Organ 1999, 77:230-234.

24. Akogbéto M, Djouaka R, Noukpo $\mathrm{H}$ : Use of agricultural insecticides in Benin. Bull Soc Pathol Exot 2005, 98:400-405.

25. Joncour G: Lutte anti-palustre au Dahomey Rapport no 13: Ministère de la Santé Publique 1959.

26. Magesa SM, Wilkest J, Minzawa AEP, Myamba J, Philip MD: Trial of pyrethroid impregnated bed nets in area of Tanzania hole endemic of malaria. Part II. Effects on vector population. Acta Trop 1990, 49:97-108.

27. WHO: Resistance of vectors and reservoirs of disease to pesticides. Tenth report of the WHO Expert Committee on Vector Biology and Control. Geneva. WHO Technical Report Series, No: 737 World Health Organization 1986.

28. RTI International: Indoor Residual Spraying (IRS) Indefinite Quantity Contract (IQC). PMI, USAID 2008.

29. Scott J, Brogdon W, Collins F: Identification of single specimens of the Anopheles gambiae complex by PCR. Am J Trop Med Hyg 1993, 49:520-529.

30. Favia G, Della Torre A, Bagayoko M, Lanfrancotti Sagnon NF, Toure $Y$, Coluzzi M: Molecular identification of sympatric chromosomal forms of Anopheles gambiae and further evidence of their reproductive isolation. Insect Mol Biol 1997, 6:377-383.

31. Martinez-Torres D, Chandre F, Williamson MS, Darriet F, Berge JB, Devonshire AL, Guillet P, Pasteur N, Pauron D: Molecular characterization of pyrethroid knockdown resistance $(k d r)$ in the major malaria vector Anopheles gambiae s.s. Insect Mol Biol 1998, 7:179-184.

32. Weill M, Malcolm C, Chandre F, Mogensen K, Berthomieu A, Marquine M, Raymond $\mathrm{M}$ : The unique mutation in ace-1 giving high insecticide resistance is easily detectable in mosquito vectors. Insect Mol Biol 2004, 13:1-7.

33. Abbott WS: A method of computing the effectiveness of an insecticide. J Am 1987, 3:302-303.

34. Awolola TS, Oyewole IO, Amajoh CN, Idowu ET, Ajayi MB, Oduola A, Manafa OU, Ibrahim K, Koekemoer LL, Coetzee M: Distribution of the molecular forms of Anopheles gambiae and pyrethroid knock down resistance gene in Nigeria. Acta 2005, 95:204-209.
35. Toure YT, Petrarca V, Traore SF, Coulibaly A, Maiga HM, Sankare O, Sow M, Di Deco MA, Coluzzi M: The distribution and inversion polymorphism of chromosomally recognized taxa of the Anopheles gambiae complex in Mali, West Africa. Parassitologia 1998, 40:477-511.

36. Wondji C, Simard F, Fontenille D: Evidence for genetic differentiation between the molecular forms $\mathrm{M}$ and $\mathrm{S}$ within the Forest chromosomal form of Anopheles gambiae in an area of sympatry. Insect Mol Biol 2002, 11:11-19.

37. Diabate A, Baldet T, Chandre C, Dabire KR, Kengne P, Guiguemde TR, Simard F, Guillet $P$, Hemingway J, Hougard JM: KDR mutation, a genetic marker to assess events of introgression between the molecular $M$ and $\mathrm{S}$ forms of Anopheles gambiae (Diptera: Culicidae) in the tropical savannah area of West Africa. J Med Entomol 2003, 40:195-198.

38. IFDC: L'état du marché des intrants agricoles au Bénin. Technical Bulletin IFDC-T70 2005, 83.

39. Djogbénou L, Dabire R, Diabate A, Kengne P, Akogbeto M, Hougard JM Chandre F: Identification and geographic distribution of the ace-1r mutation in the malaria vector Anopheles gambiae in south-western Burkina Faso, West Africa. Am J Trop Med Hyg 2008, 78:298-302.

doi:10.1186/1475-2875-9-83

Cite this article as: Yadouleton et al:: Insecticide resistance status in Anopheles gambiae in southern Benin. Malaria Journal 2010 9:83.

\section{Submit your next manuscript to BioMed Central and take full advantage of:}

- Convenient online submission

- Thorough peer review

- No space constraints or color figure charges

- Immediate publication on acceptance

- Inclusion in PubMed, CAS, Scopus and Google Scholar

- Research which is freely available for redistribution 